\title{
Living Kidney Donation in a Type 1 Dent's Disease Patient from His Mother
}

\author{
Giovanni Gambaro a, c Alessandro Naticchia a, c Pietro Manuel Ferraroa, c \\ Gionata Spagnoletti $^{b, c}$ Jacopo Romagnoli ${ }^{b, c}$ Maria Paola Salerno ${ }^{b, c}$ \\ Franco Citterio ${ }^{b, c}$ \\ a Nephrology Unit, University Hospital A. Gemelli IRCCS, Rome, Italy; \\ ${ }^{\text {b}}$ Kidney Transplantation Unit, University Hospital A. Gemelli IRCCS, Rome, Italy; \\ ${ }^{\mathrm{C}}$ Catholic University of the Sacred Heart, Rome, Italy
}

\section{Keywords}

Dent's disease $\cdot$ Kidney transplantation · Living donation · Obligate carrier

\begin{abstract}
Introduction: Dent's disease is a rare X-linked recessive disorder that manifests in childhood or early adulthood and can lead to end-stage renal disease (ESRD). It occurs in males, who are hemizygous. In patients who develop ESRD, a deceased donor kidney transplant cures the disease. Females are obligate carriers of the mutated gene, and some show a mild Dent's disease phenotype. There may be reason for concern when considering a female obligate carrier (i.e., the mother) for kidney donation because of the risk of kidney function deterioration. Case Presentation: We describe the first successful kidney transplantation involving a patient with type 1 Dent's disease and ESRD given a kidney by an obligate carrier of the gene mutation, his mother. Conclusions: After careful assessment of the female obligate carriers, intrafamilial kidney donation in Dent's disease type 1 is feasible. No deteriorating renal function in the donor was observed.

(C) 2019 The Author(s)

Published by S. Karger AG, Basel
\end{abstract}

\section{Introduction}

Dent's disease [1] is a rare X-linked recessive disorder that manifests in childhood or early adulthood. It occurs in males, who are hemizygous, while females are obligate carriers. Ten per cent of patients are de novo cases. The disease is characterized by nephrocalcinosis, calcium nephrolithiasis, hypercalciuria, low-molecular-weight (LMW) proteinuria, glycosuria, and other tubular dysfunctions - including an abnormal phosphate transport in patients who 


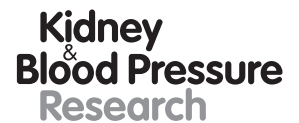

Kidney
Blood Pressure
Research \begin{tabular}{l|l}
\hline Kidney Blood Press Res 2019;44:1306-1312 \\
\hline DOI: 10.1159/000503301 & $\begin{array}{l}\text { @ 2019 The Author(s). Published by S. Karger AG, Basel } \\
\text { www.karger.com/kbr }\end{array}$ \\
\hline
\end{tabular}

Gambaro et al.: Living Donation in Dent's Disease

disclose hypophosphatemic rickets or osteomalacia. Progression to end-stage renal disease (ESRD) is common in Dent's disease patients. The disease is genetically heterogeneous, and mutations have been discovered in either the CLCN5 or the OCRL1 genes, so it is classified as type 1 or type 2, respectively. Mutations are not found in either of the 2 genes in $25 \%$ of patients with the Dent's phenotype, however [2, 3].

The chloride channel CLCN5 gene encodes CIC-5, an intracellular protein expressed in the membrane of subapical endosomes of the proximal tubule, the thick ascending limb of Henle's loop, and the collecting ducts $[4,5]$. The ClC-5 is engaged in LMW protein endocytosis [4], endosomal acidification, and lysosomal trafficking [6, 7]. The mechanisms by means of which CLCN5 mutations result in hypercalciuria, other tubule abnormalities, and ESRD are elusive. A defective apical endocytosis of PTH and 25-hydroxy D3 in the epithelium of the proximal tubule may explain the onset of hypercalciuria, kidney stones, and nephrocalcinosis [6]. Patients may progress to ESRD even without nephrocalcinosis; however, it does not seem to be responsible for renal function deterioration [8]. The hypothesis of a pathogenic involvement of podocytes has recently been advanced, [9].

The OCRL1 gene encodes a phosphatidylinositol bisphosphate 5-phosphatase. Mutations of this gene result in a deficiency of this phosphatase, which also cause a defective endosomal and lysosomal trafficking [10]. The OCRL1 gene mutations found in Lowe syndrome differ from those seen in Dent's disease type 2, however.

Virtually every patient with Dent's disease has LMW proteinuria and hypercalciuria, and nephrocalcinosis and nephrolithiasis occur in 75 and $50 \%$ of cases, respectively [11]. Progression to ESRD occurs in $30-80 \%$ of patients. This happens between the 3rd and 5th decades of life in Dent's disease type 1, while in type 2 this progression is faster, leading to ESRD by the age of 20 in $70 \%$ of cases [12]. Due to the phenomenon of lyonization, a usually very mild Dent's disease phenotype can be seen in females carrying the mutated gene. More than $50 \%$ of these females will have LMW proteinuria and hypercalciuria, while nephrocalcinosis and nephrolithiasis are rare, and ESRD has only been reported in one case [13]. So, for the most part, female carriers are asymptomatic.

A history involving an X-linked inheritance of renal stones and ESRD points to Dent's disease, which is confirmed in most cases by identifying the related CLCN5 gene or ORCL1 gene mutations.

There is no therapy targeting the molecular defects. Hypercalciuria can be treated with thiazides [14], and alkaline citrate was found to slow progression to ESRD in an animal model [15].

In patients who develop ESRD, a deceased donor kidney transplant achieves good results and the disease does not recur [16]. There may be cause for concern when considering a female obligate carrier (i.e., the mother) for living kidney donation because it is hard to say whether or not the remaining hyperfiltering "heterozygous" kidney might compensate or possibly develop a Dent's phenotype.

\section{Case Report}

A 45-year-old Caucasian male with ESRD was transplanted at our hospital, receiving a kidney from his 75-year-old mother.

His medical history included scarlet fever at 3 years of age. Urine analysis disclosed microhematuria, proteinuria, and granular casts, and he was suspected of having had poststreptococcal glomerulonephritis. The persistence of urinary abnormalities, including glycosuria, prompted a renal biopsy at the age of 15. Light microscopy revealed focal segmental glomerular sclerosis, while immunofluorescence was negative. 

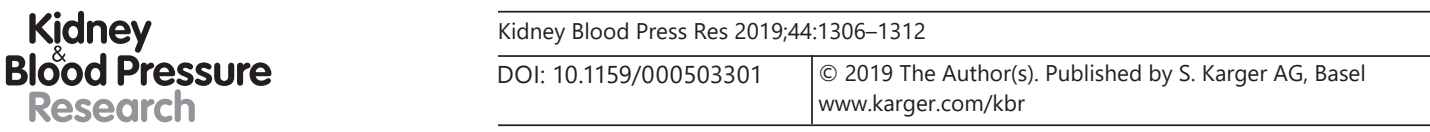

Gambaro et al.: Living Donation in Dent's Disease

Table 1. LKDPI of the CLCN5 gene mutation c.1631C>T (p.Arg467*) obligate carrier mother who donated the kidney

Donor age

Donor sex

Recipient sex

Donor eGFR

Donor SBP

Donor BMI

Donor is African American

Donor history of cigarette use

Donor and recipient biologically related

Donor and recipient are ABO incompatible

Donor/recipient weight ratio

Donor and recipient HLA-B mismatches

Donor and recipient HLA-DR mismatches

Score

LKDPI, living kidney donor profile index; BMI, body mass index; eGFR, estimated glomerular filtration rate.

A few years later, when he was 21 , the patient was also found to have hypercalciuria. He passed a stone in early adulthood. Renal US performed at the age of 42 showed multiple stones bilaterally that were $<4 \mathrm{~mm}$ in diameter. Dent's disease was suspected because a maternal uncle and cousin reportedly had renal failure.

Genetic analysis confirmed the diagnosis of Dent's disease type 1, disclosing the CLCN5 gene mutation c.1631C>T (p.Arg467*). The same mutation was found in the other affected relatives.

At 45 years of age, the patient's GFR was below $15 \mathrm{~mL} / \mathrm{min}$. The possibility of kidney transplantation from a living donor was discussed. Only 3 blood-related family members were available. A 38-year-old sister, who does not carry the CLCN5 gene mutation, was unfortunately unsuitable due to other, unrelated kidney problems. A 71-year-old maternal aunt had a GFR lower than $60 \mathrm{~mL} / \mathrm{min}$. This left only the mother, who was 75 years old and had an estimated glomerular filtration rate (eGFR) of $66-86 \mathrm{~mL} / \mathrm{min} / 1.72 \mathrm{~m}^{2}$ (serum creatinine 0.86 and $0.68 \mathrm{mg} / \mathrm{dL}$, respectively). Creatinine clearance was determined twice (68 and 101 $\mathrm{mL} / \mathrm{min}$ ). Renal nuclear scan with ${ }^{99 \mathrm{~m}} \mathrm{Tc}$-DTPA was performed. The global GFR was 100.2 $\mathrm{mL} / \mathrm{min}$ (double-blood-sampling method, 60 and $180 \mathrm{~min}$ after administration), with symmetrical contribution by the 2 kidneys (Right 51\%, Left 49\%). The mother was thus judged eligible for donation. She had hypertension controlled with a dihydropyridine calcium channel blocker.

She had a living kidney donor profile index (LKDPI) of 67 (Table 1).

As Dent's disease is an X-linked disorder, and this case was not due to a de novo mutation, patient's mother is an obligate carrier. We therefore investigated whether this proband's mother had a mild Dent's phenotype. Her proteinuria (range of 3 determinations 70-123 $\mathrm{mg} / 24 \mathrm{~h}$ ), albuminuria (range of 3 determinations 10.1-16.6 mg/24 h), LMW proteinuria ( $\beta 2$-microglobulin $170 \mu \mathrm{g} / 24 \mathrm{~h}$ ), glycosuria (absent), and calciuria (range of 3 determinations $2.57-3.10 \mathrm{mmol} / 24 \mathrm{~h}$ ) were normal, as were the renal US and CT findings. There was no evidence of stones or nephrocalcinosis. It was therefore concluded that this potential donor is a healthy carrier since she showed none of the signs or biochemical changes of the Dent's phenotype.

The risks of transplanting a kidney from a donor who is an obligate carrier of the CLCN5 gene mutation, the potential disadvantages of receiving a kidney from an elderly 
Fig. 1. Renal function in the receiving patient after kidney transplantation.

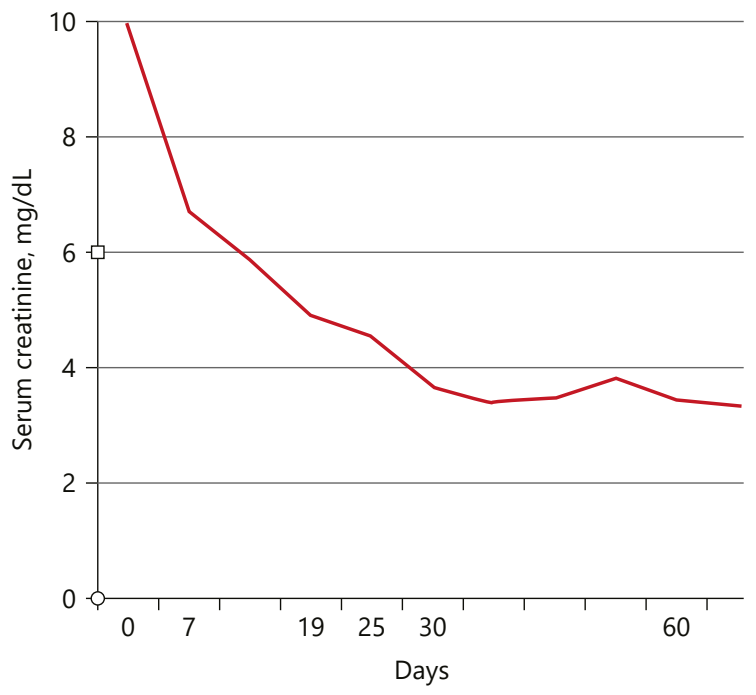

donor with a significant body discrepancy and high LKDPI, and the risks to the donor of living with only one single kidney were extensively discussed with the recipient, the donor and their families.

It was also clearly acknowledged that, to the best of our knowledge, this would have been the first kidney transplantation to a Dent's disease patient from an obligate carrier. Both mother and son were more than happy to accept the risks and benefits of transplantation.

The patient's serum creatinine was $9.91 \mathrm{mg} / \mathrm{dL}$ (eGFR $6 \mathrm{~mL} / \mathrm{min} / 1.73 \mathrm{~m}^{2}$ ) on the day before transplantation. The graft immediately produced a urine output with normal kidney perfusion, but creatinine levels were slow to decrease (Fig. 1). There was no need for hemodialysis. Since Doppler US of the kidney showed a normal perfusion and because of the gradual and constant improvement of serum creatinine, we thought it wasn't necessary to perform a biopsy. The Figure 1 shows the serum creatinine levels over the first 2 months after transplantation, when the situation became stable around the nadir of an eGFR of $20-21 \mathrm{~mL} /$ $\min / 1.73 \mathrm{~m}^{2}$. The patient was discharged on day 7 after transplantation with creatinine 6.5 $\mathrm{mg} / \mathrm{dL}$, and no episodes of acute rejection.

Immunosuppression consisted of an induction therapy based on Thymoglobulin (200 $\mathrm{mg}$ total dose), basiliximab, and steroids and maintenance therapy based on tacrolimus oncedaily with MMF and steroids. Tacrolimus trough level at 1 month post-transplant was 5.3 $\mathrm{ng} / \mathrm{mL}$.

Four months after transplantation, we stopped MMF and introduced everolimus in combination with tacrolimus and steroids aiming to reduce tacrolimus nephrotoxicity.

The donor and recipient were both positive for anti-CMV IgG at the time of transplant and, according to our local clinical practice, the patient underwent preemptive CMV prophylaxis. The patient started valganciclovir due to a positive blood PCR CMV DNA (4.596 copies/ $\mathrm{mL}$ ) detected 7 weeks after transplantation without CMV syndrome or disease, and discontinued therapy after the PCR-CMV DNA test was negative. The patient did not experience PCR CMV DNA recurrence, and blood BK viremia was stably negative.

No protocol kidney biopsy was performed during follow-up period. US evaluation at 1 year found a normal kidney for size and echogenicity, good contrast resolution between cortex and medulla, normal renal artery and vein on color Doppler ultrasound, normal resistivity index of the intrarenal vessels and normal collecting system. 


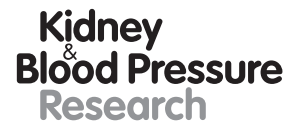

Kidney
Blood Pressure
Research \begin{tabular}{l|l}
\hline Kidney Blood Press Res 2019:44:1306-1312 \\
\hline DOI: 10.1159/000503301 & $\begin{array}{l}\text { @ 2019 The Author(s). Published by S. Karger AG, Basel } \\
\text { www.karger.com/kbr }\end{array}$ \\
\hline
\end{tabular}

Gambaro et al.: Living Donation in Dent's Disease

Now, 2 years on, he has an eGFR of $17 \mathrm{~mL} / \mathrm{min} / 1.73 \mathrm{~m}^{2}$. His current immunosuppressant treatment is based on tacrolimus $4 \mathrm{mg}$ /day and everolimus $5 \mathrm{mg}$ /day, with trough levels of 3.8 and $3.3 \mathrm{ng} / \mathrm{mL}$, respectively. Search for types I and II DSA is negative. The 24-h urine excretion of proteins is $0.98 \mathrm{~g}$, of calcium $3.8 \mathrm{mmol}$, of phosphate $28 \mathrm{mmol}$.

The donor (the patient's mother) had a peak in serum creatinine, $1.20 \mathrm{mg} / \mathrm{dL}$, on the 2 nd day after nephrectomy. Now, 2 years after her donation, she is in excellent condition, with an eGFR of $55 \mathrm{~mL} / \mathrm{min} / 1.73 \mathrm{~m}^{2}$ (serum creatinine $0.98 \mathrm{mg} / \mathrm{dL}$; cystatin C $1.42 \mathrm{mg} / \mathrm{dL}$ ), virtually no proteinuria $(62 \mathrm{mg} / 24 \mathrm{~h})$, normal urine parameters, and a normal picture on kidney Doppler US. Her blood pressure is still well controlled with the same dihydropyridine calcium channel blocker as before the donation.

\section{Discussion}

To the best of our knowledge, this is the first report of a successful kidney transplantation in a type 1 Dent's patient with ESRD given a kidney by his mother, an obligate carrier of the CLCN5 gene mutation responsible for Dent's disease.

Deciding whether or not to accept a donor with a genetic risk is a multifaceted task, given the need to balance the donor's safety against the benefits for the recipient.

This case reassures us that it is feasible to accept a kidney donation from a female carrying the CLCN5 gene mutations responsible for Dent's disease type 1 in heterozygosis (the obligate carrier). Based on this experience, this is only feasible for obligate carriers showing none of the biochemical or other signs of the disease. Although she was in her seventies, our donor had an excellent baseline e-GFR of $86 \mathrm{~mL} / \mathrm{min} / 1.73 \mathrm{~m}^{2}$ and a fairly good response postnephrectomy. In fact, the GFR halved $\left(48 \mathrm{~mL} / \mathrm{min} / 1.73 \mathrm{~m}^{2}\right)$ immediately after the donation but increased to $55 \mathrm{~mL} / \mathrm{min} / 1.73 \mathrm{~m}^{2}$ two years later, demonstrating some degree of compensation. The normal proteinuria and kidney vascularization reassure us that there is no deterioration of renal function in the donor.

We cannot be sure that an obligate carrier with a mild Dent's phenotype could respond so well, however. We would therefore only accept such donors if they are at least 60 years old because progression to ESRD in Dent's disease type 1 is slow [17], and a donor over 60 has a life expectancy that is likely to be incompatible with the time it takes for ESRD to develop.

Neither can we say for sure that a type 2 Dent's carrier could be safely allowed to donate. In this case, the potential donor would probably need to be older because type 2 Dent's disease progresses to ESRD more rapidly than type 1 [12].

In subjects at risk of nephrolithiasis, donor age has been emphasized by the guidelines as one of the criteria to consider because a younger donor is exposed to a higher risk of unfavorable outcomes [18].

As for the recipient, our case is not informative regarding the safety of transplanting such "nonstandard" organs. In fact, the transplanted kidney unfortunately did not fully recover. It functioned best 2 months after the transplantation, but even then, was only $21 \mathrm{~mL} / \mathrm{min}$. We surmise that the discrepancy between body sizes ([BSA $2.2 \mathrm{~m}^{2}$ for the recipient vs. $1.7 \mathrm{~m}^{2}$ for the donor) and the high LKDPI might have been responsible for the suboptimal renal function in the recipient.

Although we did not perform a kidney biopsy, US evaluation of renal arterial and venous anatomy and perfusion and absence of DSA are against the hypothesis of rejection. Nephrocalcinosis has been observed to be frequent in transplanted kidneys [19]. Since Dent's disease is typically associated with nephrocalcinosis, it is not unreasonable to believe that a kidney from an obligate Dent's disease carrier might be at higher risk of calcium precipitation in the renal tissue. Nephrocalcinosis is almost invariably associated with hypercalciuria [20]. Thus, the normal calcium and phosphate urinary excretion that we observed in this patient after 
transplantation does not support the idea that his graft had a higher risk of nephrocalcinosis than a "regular" transplanted kidney.

In conclusion, after carefully assessing the female obligate carriers, intrafamilial kidney donation in Dent's disease type 1 is feasible.

\section{Acknowledgment}

None.

\section{Statement of Ethics}

Subjects involved in this case report have given their informed consent.

\section{Disclosure Statement}

The authors of this manuscript have no conflicts of interest to disclose.

\section{Funding Sources}

None.

\section{Author Contributions}

All authors were in charge of the patient and the donor in different phases, before, during, and after transplantation. G.G. and F.C.: wrote the paper. A.N., P.M.F., G.S., J.R., and M.P.S.: discussed critically the draft and gave significant contributions. All authors approved the paper.

\section{References}

1 Devuyst 0, Thakker RV. Dent's disease. Orphanet J Rare Dis. 2010 Oct;5(1):28.

2 Tosetto E, Addis M, Caridi G, Meloni C, Emma F, Vergine G, et al. Locus heterogeneity of Dent's disease: OCRL1 and TMEM27 genes in patients with no CLCN5 mutations. Pediatr Nephrol. 2009 Oct;24(10):196773.

3 Solano A, Lew SQ, Ing TS. Dent-Wrong disease and other rare causes of the Fanconi syndrome. Clin Kidney J. 2014 Aug; 7(4):344-7.

4 Günther W, Lüchow A, Cluzeaud F, Vandewalle A, Jentsch TJ. ClC-5, the chloride channel mutated in Dent's disease, colocalizes with the proton pump in endocytotically active kidney cells. Proc Natl Acad Sci USA. 1998 Jul; 95(14):8075-80.

5 Devuyst O, Christie PT, Courtoy PJ, Beauwens R, Thakker RV. Intra-renal and subcellular distribution of the human chloride channel, CLC-5, reveals a pathophysiological basis for Dent's disease. Hum Mol Genet. 1999 Feb;8(2):247-57.

6 Piwon N, Günther W, Schwake M, Bösl MR, Jentsch TJ. ClC-5 Cl- -channel disruption impairs endocytosis in a mouse model for Dent's disease. Nature. 2000 Nov;408(6810):369-73.

7 Wang SS, Devuyst O, Courtoy PJ, Wang XT, Wang H, Wang Y, et al. Mice lacking renal chloride channel, CLC-5, are a model for Dent's disease, a nephrolithiasis disorder associated with defective receptor-mediated endocytosis. Hum Mol Genet. 2000 Dec;9(20):2937-45.

8 Gambaro G, Favaro S, D’Angelo A. Risk for renal failure in nephrolithiasis. Am J Kidney Dis. 2001 Feb;37(2): 233-43. 
9 Wang X, Anglani F, Beara-Lasic L, Mehta AJ, Vaughan LE, Herrera Hernandez L, et al.; Investigators of the Rare Kidney Stone Consortium. Glomerular pathology in Dent disease and its association with kidney function. Clin J Am Soc Nephrol. 2016 Dec;11(12):2168-76.

10 Erdmann KS, Mao Y, McCrea HJ, Zoncu R, Lee S, Paradise S, et al. A role of the Lowe syndrome protein OCRL in early steps of the endocytic pathway. Dev Cell. 2007 Sep;13(3):377-90.

11 Anglani F, D’Angelo A, Bertizzolo LM, Tosetto E, Ceol M, Cremasco D, et al.; Dent Disease Italian Network. Nephrolithiasis, kidney failure and bone disorders in Dent disease patients with and without CLCN5 mutations. Springerplus. 2015 Sep;4(1):492.

12 Zaniew M, Bökenkamp A, Kolbuc M, La Scola C, Baronio F, Niemirska A, et al. Long-term renal outcome in children with OCRL mutations: retrospective analysis of a large international cohort. Nephrol Dial Transplant. 2018 Jan;33(1):85-94.

13 Wrong OM, Norden AG, Feest TG. Dent's disease; a familial proximal renal tubular syndrome with lowmolecular-weight proteinuria, hypercalciuria, nephrocalcinosis, metabolic bone disease, progressive renal failure and a marked male predominance. QJM. 1994 Aug;87(8):473-93.

14 Blanchard A, Vargas-Poussou R, Peyrard S, Mogenet A, Baudouin V, Boudailliez B, et al. Effect of hydrochlorothiazide on urinary calcium excretion in dent disease: an uncontrolled trial. Am J Kidney Dis. 2008 Dec;52(6): 1084-95.

15 Gambaro G. Citrate therapy in Dent's disease. Kidney Int. 2006 May;69(10):1916.

16 Frymoyer PA, Scheinman SJ, Dunham PB, Jones DB, Hueber P, Schroeder ET. X-linked recessive nephrolithiasis with renal failure. N Engl J Med. 1991 Sep;325(10):681-6.

17 Blanchard A, Curis E, Guyon-Roger T, Kahila D, Treard C, Baudouin V, et al. Observations of a large Dent disease cohort. Kidney Int. 2016 Aug; 90(2):430-9.

18 Gambaro G, Zaza G, Citterio F, Naticchia A, Ferraro PM. Living kidney donation from people at risk of nephrolithiasis, with a focus on the genetic forms. Urolithiasis. 2019 Feb;47(1):115-23.

19 Verhulst A, Asselman M, De Naeyer S, Vervaet BA, Mengel M, Gwinner W, et al. Preconditioning of the distal tubular epithelium of the human kidney precedes nephrocalcinosis. Kidney Int. 2005 Oct;68(4):1643-7.

20 Shavit L, Jaeger P, Unwin RJ. What is nephrocalcinosis? Kidney Int. 2015 Jul;88(1):35-43. 